This is an open access article under the CC BY-NC-ND license (https://creativecommons.org/licenses/by-nc-nd/3.0/) Issue III, November 2020

ISSN 2707-9481

ISBN 978-601-323-207-2

https://doi.org/10.31643/2020.032

\author{
Maygul Kabdeshovna Medenova \\ RSE at REM «Republican Research Institute \\ for Labor Protection of the Ministry of Labor \\ and Social Protection of the Population of the Republic of Kazakhstan» \\ Republic of Kazakhstan, Email: nauka@ rniiot.kz \\ ORCID ID https://orcid.org/0000-0001-9989-6086
}

\title{
Current directions of research and prospects for the development of the science of safety and labor protection
}

\begin{abstract}
This article presents the results of research conducted by the Republican Research Institute for labor protection, within the framework of the scientific and technical program "Applied scientific research in the field of labor protection". The article is bas1ed on the results of research on the topic: "Development of scientific and methodological bases for ensuring safe work in priority sectors of the economy of the Republic of Kazakhstan "(IRN 61897/PCF-mtszn RK-OT-20). The author describes scientific developments, their content and justification of the need for implementation in production. The implementation of this program is aimed at defining a national strategy, policy and management system for occupational safety that reflects advanced scientific approaches and effective mechanisms for ensuring safe work. The results of the study will be used in the formation of a long-term strategy and concept for the development of the labor protection management system in the Republic of Kazakhstan at the state level.

Keywords: occupational safety and health, management system, occupational risk management, scientific approaches.
\end{abstract}

Cite this article as: Medenova M. K. (2020). Sovremennyye napravleniya issledovaniy i perspektivy razvitiya nauki o bezopasnosti i okhrany truda [Current directions of research and prospects for the development of the science of safety and labor protection]. Challenges of Science. Issue III, p.: 206-209. (In Russian). https://doi.org/10.31643/2020.032

\author{
Майгуль Кабдешовна Меденова \\ РГП на ПХВ «Республиканский \\ научно-исследовательский институт по охране \\ труда Министерства труда и социальной защиты населения Республики Казахстан», \\ Республика Казахстан, Email: nauka@ rniiot.kz \\ ORCID ID https://orcid.org/0000-0001-9989-6086
}

\section{Современные направления исследований и перспективы развития науки о безопасности и охраны труда}

Абстракт. В настоящей статье представлены результаты проведенных научно-исследовательских работ Республиканским НИИ по охране труда, в рамках научно-технической программы «Прикладные научные исследования в области охраны труда». Статья подготовлена по результатам научно-исследовательских работ 
по теме: «Разработка научно-методических основ обеспечения безопасного труда в приоритетных секторах экономики Республики Казахстан» (ИРН 61897/ПЦФ-МТСЗН РК-ОТ-20). Автором описаны научные разработки, их содержание и обоснование необходимости внедрения на производстве. Реализация данной программы направлена на определение национальной стратегии, политики и системы управления охраной труда, отражающей передовые научные подходы, эффективные механизмы обеспечения безопасного труда. Результаты исследования будут использованы при формировании долгосрочной стратегии и концепции развития системы управления охраной труда в Республике Казахстан на государственном уровне.

Ключевые слова: безопасность и охрана труда, система управления, управление профессиональными рисками, научные подходы.

В 2020 году РГП на ПХВ «Республиканский научно-исследовательский институт по охране труда Министерства труда и социальной защиты населения Республики Казахстан» в рамках приоритетного научного направления «Наука о жизни и здоровье» завершил реализация третьего, заключительного этапа научно-технической программы «Прикладные научные исследования в области охраны труда» на тему: «Разработка научно-методических основ обеспечения безопасного труда в приоритетных секторах экономики Республики Казахстан».

Актуальность темы исследования заключается в необходимости реализации государственной политики в области охраны труда и должна производится на системной основе, т.е. необходимо построение инновационной Системы управления охраной труда (далее - СУОТ) опыт применения которой на примере ряда развитых стран показывает, что наибольший эффект в профилактике производственного травматизма.

На сегодняшний день, действующие в Казахстане международные стандарты, регулирующие вопросы систем управления охраной труда (OHSAS-18001, 45001, МОТ-СУОТ 2001, ANSI Z10 и т.п.), внедряемые на отечественных предприятиях (на добровольной основе), не адаптированы к особенностям отечественных производств, не учитывают отраслевую специфику производства, носят затратный характер и, в целом, вызывают много вопросов и сложностей.

В 2018 году разработаны предварительные проекты интегрированной СУОТ на основе управления профессиональными рисками в приоритетных секторах экономики РК, дифференцированной в зависимости от ВЭД и размера предприятия. В 2019 году разработаны проекты документов СУОТ (в зависимости от размерности предприятий); методика и план внедрения СУОТ. Проведено внедрение СУОТ на 20-ти пилотных предприятиях различной размерности и видов экономической деятельности (транспорт, строительство, горнодобывающая и обрабатывающая промышленность, сельское хозяйство).

На третьем этапе исследований, в 2020 году, была оценена эффективность внедренной СУОТ и сформирован комплекс методических документов национальной системы обеспечения безопасного труда на основе управления профессиональными рисками.

В данных целях были разработаны критерии оценки эффективности, которые составили комплект, состоящий из пяти критериев, охватывающих все аспекты внедряемой СУОТ (своевременность, качество и контроль выполнения процедур элементов СУОТ, эффективность управления профессиональными рисками, экономическая эффективность).

На основе данных критериев была разработана Методика внедрения интегрированной СУОТ установленным законодательным требованиям, для чего, к каждому критерию был разработан ряд показателей. Показатели, формирующие каждый критерий, определяются на основе количественного значения, вычисляемого различными способами (с применением формул, уравнений, присваиванием баллов) [1].

По результатам вычислений данных по каждому критерию, производится занесение в Протоколы и выводится среднее значение, также приводимое в Протоколе. В итоговый Протокол оценки эффективности СУОТ, кроме расчетных данных, предусмотрено внесение информации о том, в связи с какими нарушениями законодательства или несоблюдением каких процедур СУОТ, произошло снижение эффективности. Это дает возможность осуществить самоконтроль и обратить внимание на определенные недостатки с целью их исключения и проведения корректирующих мероприятий.

Результаты оценки по каждому критерию распределяются в соответствии с показателем эффективности. Степень эффективности ранжирована в зависимости от процентного значения. 
Предлагается ежегодное осуществление оценки эффективности функционирования СУОТ работодателем самостоятельно или с привлечением экспертов. В связи с этим, информация оценивается за определенный период (с момента внедрения СУОТ или предыдущей оценки эффективности).

Таким образом, данная методика рекомендована для применения в рамках процедур СУОТ и позволит работодателям осуществлять мониторинг качества и своевременности осуществляемых мероприятий и оценивать эффективность контроля.

В целях автоматизации процесса расчета данной методики, подготовлены специальные формы с помощью программы Microsoft EXCEL. Программа предназначена для ввода данных, осуществляет автоматический расчет эффективности по каждому показателю, критерию, а также выводится общее процентное значение эффективности СУОТ с автоматическим присвоением ранжированной оценки эффективности.

При оценке эффективности внедрения и обеспечении функционирования СУОТ в качестве методического документа Республиканским НИИ по охране труда была разработана «Методика SWOT - анализа внедрения системы управления охраной труда на основе управления профессиональными рисками», которая позволяет специалистам скорректировать стратегию деятельности предприятии в области охраны труда [2].

Кроме того, с целью повышения квалификации руководящих работников и лиц, ответственных за обеспечение безопасности и охраны труда по вопросам оценки эффективности внедренной СУОТ на предприятиях Республики Казахстан, разработана Учебная программа и Учебный план для проведения семинаров-тренингов на тему: «Оценка эффективности интегрированной системы управления охраной труда на основе управления профессиональными рисками».

Данная учебная программа позволит эффективно обучить навыкам системно выявлять и учитывать факторы, влияющие на безопасность труда и определять необходимую стратегию управления охраной труда.

Применение учебной программы на производстве даст возможность специалистам обеспечивать функционирование и развитие СУОТ в качестве самоорганизующейся системы и реализовывать на практике концепцию «непрерывного совершенствования», системно учитывать результаты работы ее элементов и своевременно разрабатывать, и осуществлять корректирующие мероприятия.

В результате научных исследований был сформирован научно-обоснованный комплекс методических документов национальной СУОТ в РК, включающий документы:

- проект документов научно-обоснованной СУОТ на основе УПР в зависимости от размера предприятия и его основного вида деятельности, для организаций, осуществляющих производственную деятельность со штатной численностью более 50 и менее 50 человек; осуществляющих непроизводственную деятельность со штатной численностью более 50 человек и менее 50 человек;

- Методика планирования комплекса мероприятий по охране труда на основе управления профессиональными рисками по снижению уровня производственного травматизма на предприятиях, включая комплекс мероприятий. В методике приведен порядок планирования превентивных мер. Методика разработана в соответствии с Директивой 89/391/ЕЭС «О введении мер, содействующих улучшению безопасности и гигиены труда работников на производстве», на которой основаны трудовые нормы европейских стран;

- проект Концепции безопасного труда в Республике Казахстан до 2030 года, включающий основные принципы и подходы, определяющие наиболее эффективные способы и методы решения стратегически важных задач в области обеспечения безопасного труда на государственном уровне;

Результативность реализации НТП представлена полным объемом разработанных материалов методической и концептуально-стратегической направленности, новизна которых подтверждена 8 свидетельствами о госрегистрации авторских прав, изданием научной монографии, опубликованием научных статей, в том числе в рецензируемых зарубежных научных изданиях с ненулевым импактфактором.

Таким образом в полной мере достигнута цель проекта - построение системы управления охраной труда на основе эффективной интеграции мер государственного регулирования, возможностей практической реализации на производстве и научных инноваций в обеспечении безопасного труда. 
Ссылка на данную статью: Меденова М. К. (2020) Современные направления исследований и перспективы развития науки о безопасности и охраны труда. Материалы Международной практической интернет-конференции «Актуальные проблемы науки» [Challenges of Science]. Выпуск III, стр. 206-209. https://doi.org/10.31643/2020.032

\section{Литературы}

[1] Айткенова Г. Т., Рахимов Е. Ж., Елубаев Д.К. Апробация новой интегрированной системы управления охраной труда на основе управления профессиональными рисками//журнал «Вестник КазАТК» «Казахская академия транспорта и коммуникаций им. М.Тынышпаева». -2020. -№ 3(114), С. 87-94.

[2] Кантарбаева А.Д., Тащегулов Ж.Б., Оспанов E.A. SWOT - анализ системы управления охраной труда на основе управления профессиональными рисками птицефабрики//Вопросы развития сфер образования, науки и культуры: теория, практика, опыт: Тезисы докладов Международной научно-практической конференции г. Нур-Султан, 2020. C. $48-52$.

\section{References}

[1] Aytkenova G. T., Rakhimov Ye. ZH., Yelubayev D.K. Aprobatsiya novoy integrirovannoy sistemy upravleniya okhranoy truda na osnove upravleniya professional'nymi riskami [Approbation of a new integrated OSH management system based on occupational risk management] // zhurnal «Vestnik KazATK» «Kazakhskaya akademiya transporta i kommunikatsiy im. M.Tynyshpayeva» [Journal "Vestnik KazATK" Kazakh Academy of Transport and Communications named after M. Tynyshpayev"]. -2020. -№ 3(114). P. 87-94. (In Russian).

[2] Kantarbayeva A.D., Tashchegulov ZH.B., Ospanov Ye.A. SWOT - analiz sistemy upravleniya okhranoy truda na osnove upravleniya professional'nymi riskami ptitsefabriki [SWOT - analysis of the OSH management system based on the management of professional risks of the poultry farm] // Voprosy razvitiya sfer obrazovaniya, nauki i kul'tury: teoriya, praktika, opyt: Tezisy dokladov Mezhdunarodnoy nauchno-prakticheskoy konferentsii g. Nur-Sultan [Issues of the development of education, science and culture: theory, practice, experience: Abstracts of the International Scientific and Practical Conference in Nur-Sultan], 2020. P.48-52. (In Russian). 